\title{
THE
}

2012

\section{Antiamoebic properties of the actinomycete metabolites echinomycin A and tirandamycin A}

\author{
Avelina Espinosa \\ Aaron M. Socha \\ University of Rhode Island \\ Erica Ryke \\ David C. Rowley \\ University of Rhode Island, drowley@uri.edu
}

Follow this and additional works at: https://digitalcommons.uri.edu/bps_facpubs

This is a pre-publication author manuscript of the final, published article.

Terms of Use

All rights reserved under copyright.

\section{Citation/Publisher Attribution}

Espinosa, A., Socha, A.M., Ryke, E. et al. Parasitol Res (2012) 111: 2473. https://doi.org/10.1007/ s00436-012-3019-2

Available at: https://doi.org/10.1007/s00436-012-3019-2

This Article is brought to you for free and open access by the Biomedical and Pharmaceutical Sciences at DigitalCommons@URI. It has been accepted for inclusion in Biomedical and Pharmaceutical Sciences Faculty Publications by an authorized administrator of DigitalCommons@URI. For more information, please contact digitalcommons-group@uri.edu. 


\title{
Antiamoebic properties of the actinomycete metabolites echinomycin A and tirandamycin A
}

\author{
Avelina Espinosa $a,{ }^{a}$, Aaron M. Socha ${ }^{b, c}$, Erica Ryke $^{a}$, and David C. Rowley ${ }^{b}$ \\ aDepartment of Biology, Roger Williams University, One Old Ferry Road, Bristol, RI 02809, USA \\ ${ }^{b}$ Department of Biomedical and Pharmaceutical Sciences, College of Pharmacy, University of \\ Rhode Island, Kingston, RI 02881, USA
}

\section{Abstract}

Entamoeba histolytica infects 50 million people per year, causing 100,000 deaths worldwide. The primary treatment for amoebiasis is metronidazole. However, increased pathogen resistance, combined with the drug's toxic side effects encourages a search for alternative therapeutic agents. Secondary metabolites from marine bacteria are a promising resource for anti-protozoan drug discovery. In this study, extracts from a collection of marine-derived actinomycetes were screened for antiamoebic properties and the activities of antibiotics echinomycin A and tirandamycin A are shown. Both antibiotics inhibited the in vitro growth of a $E$. histolytica laboratory strain (HM-1:IMSS) and a clinical isolate (Colombia, Col) at 30 to $60 \mu \mathrm{M}$ concentrations. EIC $_{50}$ (estimated inhibitory concentration) values were comparable for both antibiotics (44.3-46.3 $\mu \mathrm{M}$ ) against the E. histolytica clinical isolate.

\section{Keywords}

Entamoeba; echinomycin A; tirandamycin A; marine actinomycetes; antiamoebic drugs; marine extracts; in vitro efficacy

\section{Introduction}

Entamoeba histolytica, the causative agent of amoebic dysentery, is a parasitic contaminant of food, water, and soil. Upon colonizing the intestine of a primate host, Entamoeba cysts metamorphose into disease-causing trophozoites. The parasite infects $12 \%$ of the world's population. Annually, 50 million patients require clinical treatment and up to 100,000 cases result in mortality (Walsh 1986; Stanley 2003; Haque et al. 2003; Cotruvo et al. 2004, Ximénez et al. 2009). Approximately $90 \%$ of patients with mild to moderate amoebic symptoms can be treated with metronidazole or other nitroimidazole derivatives. Currently, luminal amebicides (e.g. diloxanide furoate) are effective on intestinal lumen trophozoites but not capable to reach tissue ameba (Pritt and Clark 2008; Kenny and Kelly 2009); tissue amebicides (e.g. metronidazole, dehydroemetine, chloroquine, nitazoxanide) are effective in the treatment of invasive amebiasis but not able to control luminal trophozoites (Pritt and Clark 2008; Kenny and Kelly 2009). Close to ninety percent of patients with mild to moderate amoebic symptoms respond to metronidazole and other nitroimidazole derivatives. Because of misdiagnoses and asymptomatic carriers (host non-pathogenic E. dispar instead of the infective E. histolytica) in resource-limited countries, overtreatment with both drugs is

*Corresponding Author: Avelina Espinosa, Department of Biology, Roger Williams University, One Old Ferry Road, Bristol RI 02809, Telephone: 1-401-254-3137, Fax: 1-401-254-3310, aespinosa@ rwu.edu.

${ }^{\mathrm{c}}$ Current affiliation: Department of Chemistry and Chemical Technology, Bronx Community College, Bronx NY 10453 
common (Pritt and Clark 2008). No clinical reports exist on E. histolytica resistance to metronidazole; however, in vitro metronidazole-resistant $E$. histolytica strains have been selected (Wassmann et al. 1999). Resistance in hospital strains of Trichomonas vaginalis, Giardia lamblia, as well as in anaerobic bacteria (i.e., Clostridium sp., Bacillus fragilis has been reported (Bendesky et al. 2002; Crowell et al. 2003; Ali and Nozaki 2007). Although some toxic side effects, neurological, reproductive and potential carcinogenic concerns have been reported for metronidazole and its derivatives (Bendesky et al. 2002), the strongest rationale for the search/design of novel antiamebic compounds is a drug that manages both invasive and luminal amebiasis. Anaerobic pathogens have evolved adaptive metabolic enzymes that differ from vertebrates, which could be ideal targets of novel drug discovery and design (Ali and Nozaki 2007).

Secondary metabolites produced by actinobacteria have guided the development of numerous clinically-used antimicrobial agents (Bérdy 2005). Interestingly, the parent compound of metronidazole, the nitroimidazole azomycin, was isolated from Streptomyces eurocidicus in the 1950s (Osato et al. 1955). In addition to their effectiveness as antibacterial agents, actinomycete metabolites have recently attracted attention as antiparasitic agents. A screening study of 400 compounds isolated from soil-dwelling microbes revealed the potent and selective antitrypanosomal activity of ten structurally diverse metabolites (Otoguro et al. 2008). Salinosporamide A, produced by the marine actinomycete Salinispora tropica, strongly inhibits erythrocytic stages of the of the human malaria parasite Plasmodium falciparum, perhaps through interactions with the 20 S proteasome (Prudhomme et al. 2008)

Protistan grazing poses a significant environmental pressure on marine bacterial communities, and recent evidence supports that actinobacteria may not be as susceptible to protists' attack as other types of bacteria (Fenical and Jensen 2006). Chemical defenses may be partly responsible for these findings. For example, the bacterial metabolite violacein has been shown to reduce protozoan grazing (Matz et al. 2004). These findings suggest that new antiamoebic compounds can be identified from increased investigations of microbial metabolites. In a search for such agents, we recently undertook a screening of chemical extracts derived from fermentations of actinomycetes isolated from marine coastal sediments. Herein we report the isolation and purification of two antibiotics, echinomycin A and tirandamycin A, and their inhibitory effect on of E. histolytica trophozoites in vitro.

\section{Materials and Methods}

All reagents and solvents were purchased from Fisher-Scientific and were analytical grade. UV spectra were recorded on a DU 800 spectrophotometer (Beckman-Coulter), and IR spectra were acquired on a Nexus 470 FT-IR (Thermo Nicolet). NMR spectra were recorded on a Bruker Biospin spectrometer $\left(400 \mathrm{MHz}\right.$ for ${ }^{1} \mathrm{H}, 100 \mathrm{MHz}$ for ${ }^{13} \mathrm{C}$ ) and were referenced to residual solvent signals with resonances at ${ }^{1} \mathrm{H} /{ }^{13} \mathrm{C}=\delta 7.24 / 77.0\left(\mathrm{CDCl}_{3}\right)$. ESI (electrospray ionization) mass spectrometry was accomplished in 50:50 acetonitrile/water (+ $0.1 \%$ formic acid) on a Mariner@ mass spectrometer (Applied Biosystems). HPLC (high performance liquid chromatography) was performed using a Waters 600 pump and a 486 tunable absorbance detector using a Waters X-Terra ${ }^{\circledR}$ Prep RP18 column $(5$ mm $19 \times 100$ $\mathrm{mm})$.

\section{Marine actinomycete strain collection, cultivation, and biological screening}

A library of marine actinomycetes was isolated from marine sediments collected in Fisher's Island Sound, New York. Individual strains were isolated using heat shock and desiccation methods to select for Gram-positive bacteria (Ceri 1999; LaPlante and Rybak 2004; Thelaus et al. 2008). Pure colonies were isolated on YP marine agar (1 $\mathrm{g}$ yeast extract, $5 \mathrm{~g}$ peptone, $15 \mathrm{~g}$ agar per $1 \mathrm{~L}$ of synthetic sea water (Instant Ocean; $36 \mathrm{~g}$ per L)) supplemented with 
cycloheximide to suppress fungal growth. A total of fifty-five isolates that morphologically resembled Streptomyces and Micromonospora spp. were individually cultured in $1 \mathrm{~L}$ of yeast-peptone marine media. After approximately 5-8 days of growth, cells were removed by filtration over Celite, and culture broths were extracted with $500 \mathrm{~mL}$ ethyl acetate. The resulting extracts were stored in DMSO (dimethyl sulfoxide) at $-20^{\circ} \mathrm{C}$ and tested for inhibition of amoebic growth (Espinosa et al. 2001, 2004, 2009) against E. histolytica HM-1:1MSS (standard strain; Espinosa et al. 2001, 2004, 2009) and E. histolytica Col (clinical isolate from a Colombian patient, obtained from NYU, Dan Eichinger laboratory). The extracts of two Streptomyces strains, isolates URI-F11 and URI-F39, showed inhibitory activity in an in vitro trophozoite growth assay, and were selected for further chemical investigation. Strain URI-F11 was isolated from a marine sediment sample collected from a depth of $12 \mathrm{~m}$ in Fisher's Island Sound, New York $\left(41^{\circ} 17^{\prime} 00^{\prime \prime} \mathrm{N}, 72^{\circ} 2^{\prime} 11^{\prime \prime} \mathrm{W}\right)$ and identified as a Streptomyces sp. by $16 \mathrm{~S}$ rRNA sequence comparison (deposited with GenBank as Accession No. JF939719, Socha et al. 2007). Streptomycete strain URI-F39 strain was isolated and identified as previously described (Socha et al. 2009).

\section{Purification and structure identification of tirandamycin A and echinomycin A antibiotics}

Strain URI-F11 was cultivated in sixteen $1 \mathrm{~L}$ cultures for 7 days at $155 \mathrm{RPM}$ and $24^{\circ} \mathrm{C}$ in YP marine broth. The cells were removed by cheesecloth filtration, and the broth was partitioned between ethyl acetate and $\mathrm{H}_{2} \mathrm{O}$. The organic layer was concentrated in vacuo to yield $800 \mathrm{mg}$. The extract was separated by flash chromatography using a $20-100 \%$ gradient of methanol in $\mathrm{H}_{2} \mathrm{O}$ (HP-20-SS Diaion ${ }^{\circledR}$ resin, Supelco). Reversed-phase HPLC of the $80 \%$ methanol fraction using 50-100\% acetonitrile in $\mathrm{H}_{2} \mathrm{O}$ yielded tirandamycin $\mathrm{A}(9.6 \mathrm{mg})$.

Tirandamycin was characterized by ${ }^{1} \mathrm{H}$ and ${ }^{13} \mathrm{C}$ NMR spectral comparison to the literature values (MacKellar et al. 1971). The UV and IR spectra were also identical to the published values (Meyer 1971; Lee and Rinehart 1980). A molecular weight of $418.2[\mathrm{M}+\mathrm{H}]+124$ confirmed the structure. Echinomycin A was isolated from URI F39 strain as previously described (The NMR spectra for tirandamycin A and echinomycin A corroborated their chemical composition, supplementary Fig S1, Socha et al. 2009).

\section{In vitro inhibitory assay}

Trophozoites from E. histolytica HM-1:IMSS and E. histolytica Colombia (Col), isolated from a Colombian patient) were cultured under axenic conditions in flat-bottomed 48-well plates containing $1.4 \mathrm{ml}$ of Diamond's TYI-S-33 medium as previously described (Espinosa et al. 2001, 2004, 2009). Trophozoites in log phase were used in all experiments. Growth counts were averaged from three replicate wells and three separate experiments. Amoebic cultures were closely examined to verify absence of bacterial contamination in tubes. To determine inhibition of $E$. histolytica growth, standard culture tubes containing an initial inoculation of $5 \times 10^{3}$ trophozoites were grown for 48 and 72 hrs in TYI-S-33 (alone) or supplemented with $30 \mu \mathrm{M}$ echinomycin A, $30 \mu \mathrm{M}$ tirandamycin $\mathrm{A}, 60 \mu \mathrm{M}$ echinomycin $\mathrm{A}$, or $60 \mu \mathrm{M}$ tirandamycin A, and counted using a hemocytometer. Metronidazole at a concentration of $20 \mu \mathrm{M}$ was used as positive control of inhibition (Espinosa et al. 2001, 2004, 2009). All test compounds were dissolved in DMSO; a similar volume of DMSO was added to control wells of ameba (data not shown) to discard toxicity due to the solvent.

\section{Results}

The growth inhibitory properties of pure echinomycin A (Fig 1A) and tirandamycin A (Fig 1B) were measured against E. histolytica HM-1:IMSS (Espinosa et al. 2001, 2004, 2009) and $E$. histolytica Col. The latter is a clinical isolate derived from a Colombian patient (obtained from NYU, Dan Eichinger laboratory). Each compound inhibited the growth of 
both E. histolytica strains at 30 and $60 \mu \mathrm{M}$ concentrations (Figs 2, 3). A $60 \mu \mathrm{M}$ concentration of echinomycin A inhibited $71.1 \%$ and $67.6 \%$ of trophozoites, respectively (Fig 2, Table 1). A $60 \mu \mathrm{M}$ treatment with tirandamycin A resulted in a slightly stronger inhibition, demonstrating a $84.2 \%$ reduction in growth of E. histolytica HM-1:IMSS and $64.8 \%$ reduction in growth by $E$. histolytica $\mathrm{Col}$ (Fig 3, Table 1 ). $\mathrm{EIC}_{50}$ values were comparable for both antibiotics $(44.3-46.3 \mu \mathrm{M})$ against E. histolytica Col (Table 1). $\mathrm{EIC}_{50}$ is defined as the estimated inhibitory concentrations of drug required to inhibit 50\% amoebic growth.

\section{Discussion}

Secondary metabolites produced by marine actinomycetes represent a promising resource for anti-parasitic drug discovery (Bérdy, 2005; Fenical and Jensen 2006; Otoguro et al. 2008; Prudhomme et al. 2008). This is the first investigation of actinomycete metabolites in the context of amoebic infections. An intial testing of extracts from a panel of 55 marine actinomycetes revealed the antiamoebic activity of echinomycin A and tirandamycin A against E. histolytica.

Echinomycin A is a potent antitumor and antibacterial agent that exerts its activity via DNA bisintercalation (Waring and Wakelin 1974). As such, echinomycin A has been shown to inhibit vertebrate DNA replication, chromatin decondensation, and transcription (May et al. 2004). The antiamoebic activity of echinomycin A could be due to the fact that amoeba are highly metabolic cells, which replicate 2-3 times per day (Ong and Wolfson, 1970; Austin and Warren 1983). Echinomycin has been tested in mice against methicillin-resistant Staphylococus aureus (MRSA) peritoneal infections and shown an $\mathrm{ED}_{50}$ of $0.5-1.3 \mathrm{mg} / \mathrm{kg}$ with little toxicity (Park et al. 2008).

Tirandamycin A inhibits chain initiation and elongation of bacterial RNA polymerase without acting on mammalian polymerases (Reusser 1976). Three tirandamycins isolated from Streptomyces sp. 17944 inhibited the parasitic nematode Brugia malayi at $30 \mu \mathrm{M}$ concentrations (Yu et al. 2011). The antibiotics affected the Asparagine tRNA synthetase, which suggests that the mechanism of action in E. histolytica could be through affecting RNA associated enzymes.

As compared to echinomycin A and tirandamycin A, metronidazole is a more potent inhibitor of tropozoite growth. However, toxic side effects and increasing metronidazole resistance by parasitic microbes (Bendesky, 2002; Crowell 2003; Haque et al. 2003; Ali and Nozaki 2007) limit it clinical use. These results suggest that both echinomycin A and tirandamycin A could be pursued as alternative treatments for amoebiasis.

\section{Supplementary Material}

Refer to Web version on PubMed Central for supplementary material.

\section{Acknowledgments}

We thank Regine LanFranchi for technical assistance. The E. histolytica HM-1:IMSS strain was provided by Sam Stanley and Lynne Foster at Washington University, St Louis, MO, USA. The E. histolytica Col strain was obtained from Dan Eichinger at New York University, NY, USA. A. Espinosa was supported by the RI-INBRE Award \# 2P20RR016457-10 and 2P20RR016457-11 from the National Center for Research Resources (NCRR), NIH. The content of this report is solely the responsibility of the authors and does not necessarily represent the official views of the NCRR or the NIH. This research was further supported by NOAA Grant NA04OAR4600193 to D. Rowley. The RI-INBRE Core Facility used in this study was funded by the NIH, NCRR [Grant P20-RR016457]. 


\section{References}

Ali V, Nozaki T. Current therapeutics, their problems, and sulfur-containing-amino-acid metabolism as a novel target against infections by "amitochondriate" protozoan parasites. Clin Microbiol Rev. 2007; 20:164-187. [PubMed: 17223627]

Austin CJ, Warren LG. Am J Trop Med Hyg. 1983; 32:507-511. [PubMed: 6305219]

Bendesky A, Menendez D, Ostrosky-Wegman P. Is metronidazole carcinogenic? Mutat Res. 2002; 511:133-144. [PubMed: 12052431]

Bérdy J. Bioactive microbial metabolites. J Antibiot. 2005; 58:1-26. [PubMed: 15813176]

Ceri H, Olson ME, Stremick C, Read RR, Morck DW, Buret A. The Calgary Biofilm Device: new technology for rapid determination of antibiotic susceptibilities of bacterial biofilms. J Clin Microbiol. 1999; 37:1771-1776. [PubMed: 10325322]

Cotruvo, JA.; Dufour, A.; Rees, G.; Bartram, J.; Carr, R.; Cliver, DO.; Craun, GF.; Fayer, R.; Gannon, VPJ., editors. Waterborne zoonoses: identification, causes and control. World Health Organization with IWA Publishing; London: 2004. p. 1-528.

Crowell AL, Sanders-Lewis KA, Secor WE. In vitro metronidazole and tinidazole activities against metronidazole-resistant strains of Trichomonas vaginalis. Antimicrob Agents Chemother. 2003; 47:1407-1409. [PubMed: 12654679]

Espinosa A, Yan L, Zhang ZL, Foster L, Clark D, Li E, Stanley SL Jr. The bifunctional Entamoeba histolytica alcohol dehydrogenase 2 (EhADH2) protein is necessary for amoebic growth and survival and requires an intact C-terminal domain for both alcohol dehydrogenase and acetaldehyde dehydrogenase activity. J Biol Chem. 2001; 276:20136-20143. [PubMed: 11274185]

Espinosa A, Clark D, Stanley SL Jr. Entamoeba histolytica alcohol dehydrogenase 2 (EhADH2) as a target for anti-amoebic agents. J Antimicrob Chemother. 2004; 54:56-59. [PubMed: 15150165]

Espinosa A, Perdrizet G, Paz-y-Miño-C G, Lanfrachi R, Phay M. Effects of iron depletion on Entamoeba histolytica alcohol dehydrogenase 2 (EhADH2) and trophozoite growth: implications for antiamoebic therapy. J Antimicrob Chemother. 2009; 63:675-678. [PubMed: 19218278]

Fenical W, Jensen PR. Developing a new resource for drug discovery: marine actinomycete bacteria. Nature Chem Biol. 2006; 2:666-673. [PubMed: 17108984]

Haque R, Huston CD, Hughes M, Houpt E, Petri WA. Amebiasis. N Engl J Med. 2003; 348:15651573. [PubMed: 12700377]

Kenny JM, Kelly P. Protozoal gastrointestinal infections. Medicine. 2009; 37:599-602.

LaPlante KL, Rybak MJ. Clinical glycopeptide-intermediate staphylococci tested against arbekacin, daptomycin, and tigecycline. Diagn Microbiol Infect Dis. 2004; 50:125-130. [PubMed: 15474322]

Lee VJ, Rinehart KL Jr. C NMR spectra of streptolydigin, tirandamycin, and related degradation products. J Antibiot. 1980; 33:408-415. [PubMed: 6902724]

MacKellar FA, Grostic MF, Olson EC, Wnuk RJ. J Am Chem Soc. 1971; 93:4943-4945. [PubMed: 5118218]

Matz C, Deines P, Boenigk J, Arndt H, Eberl L, Kjelleberg S, Jürgens K. Effect of violacein-producing bacteria on survival and feeding of bacterivorous nanoflagellates. Appl Environ Microbiol. 2004; 70:1593-1599. [PubMed: 15006783]

May LG, Madine MA, Waring MJ. Echinomycin inhibits chromosomal DNA replication and embryonic development in vertebrates. Nucleic Acids Res. 2004; 32:65-72. [PubMed: 14704344]

Meyer CE. Tirandamycin, a new antibiotic isolation and characterization. J Antibiot. 1971; 24:558560. [PubMed: 5092790]

Ong LK, Wolfson N. Some Growth characteristics of axenically cultivated Entamoeba histolytica-like amebae (Huff strain). J Parasitol. 1970; 56:897-903. [PubMed: 5504529]

Osato T, Ueda M, Fukuyama S, Yagishita K, Okami Y, Umezawa H. Production of tertiomycin (a new antibiotic substance), azomycin and eurocidin by $S$. eurocidicus. J Antibiot. 1955; 8:105-109. [PubMed: 13286189]

Otoguro K, Ishiyama A, Namatame M, Nishihara A, Furusawa T, Masuma R, Shiomi K, Takahashi Y, Yamada H, Omura S. Selective and potent in vitro antitrypanosomal activities of ten microbial metabolites. J Antibiot. 2008; 61:372-378. [PubMed: 18667785] 
Park Y, Shin W, Kim S. In vitro and in vivo activities of echinomycin against clinical isolates of Staphylococcus aureus. J Antimicrob Chemother. 2008; 61:163-168. [PubMed: 17967852]

Pritt BS, Clark CG. Amebiasis. Mayo Clin Proc. 2008; 83:1154-1159. [PubMed: 18828976]

Prudhomme J, McDaniel E, Ponts N, Bertani S, Fenical W, Le Roch K. Marine actinomycetes: a new source of compounds against the human malaria parasite. PloS ONE. 2008; 3:e2335. [PubMed: 18523554]

Reusser F. Tirandamycin, an inhibitor of bacterial ribonucleic acid polymerase. Antimicrob Agents Chemother. 1976; 10:618-622. [PubMed: 791108]

Socha AM, Long RA, Rowley DC. Bacillamides from a Hypersaline Microbial Mat Bacterium. J Nat Prod. 2007; 70:1793-1795. [PubMed: 17988095]

Socha AM, LaPlante KL, Russell DJ, Rowley DC. Structure activity studies of echinomycin antibiotics against drug-resistant and biofilm-forming Staphylococcus aureus and Enterococcus faecalis. Bioorg Med Chem Lett. 2009; 19:1504-1507. [PubMed: 19185486]

Stanley SL Jr. Amoebiasis. Lancet. 2003; 361:1025-1034. [PubMed: 12660071]

Thelaus J, Forsman M, Andersson A. Role of productivity and protozoan abundance for the occurrence of predation-resistant bacteria in aquatic systems. Microb Ecol. 2008; 56:18-28. [PubMed: 17874304]

Waring MJ, Wakelin LP. Nature. 1974; 252:653-657. [PubMed: 4437614]

Wassmann C, Hellberg A, Tannich E, Bruchhaus I. Metronidazole resistance in the protozoan parasite Entamoeba histolytica is associated with increased expression of iron-containing superoxide dismutase and peroxiredoxin and decreased expression of ferredoxin 1 and flavin reductase. J Biol Chem. 1999; 274:26051-26056. [PubMed: 10473552]

Yu Z, Vodanovic-Jankovic S, Ledeboer N, Huang S, Rajski SR, Kron M, Shen B. Tirandamycins from Streptomyces sp. 17944 inhibiting the parasite Brugia malayi asparagine tRNA synthetase. Org Lett. Mar.2011 pub ahead of print. 10.1021/ol200420u 


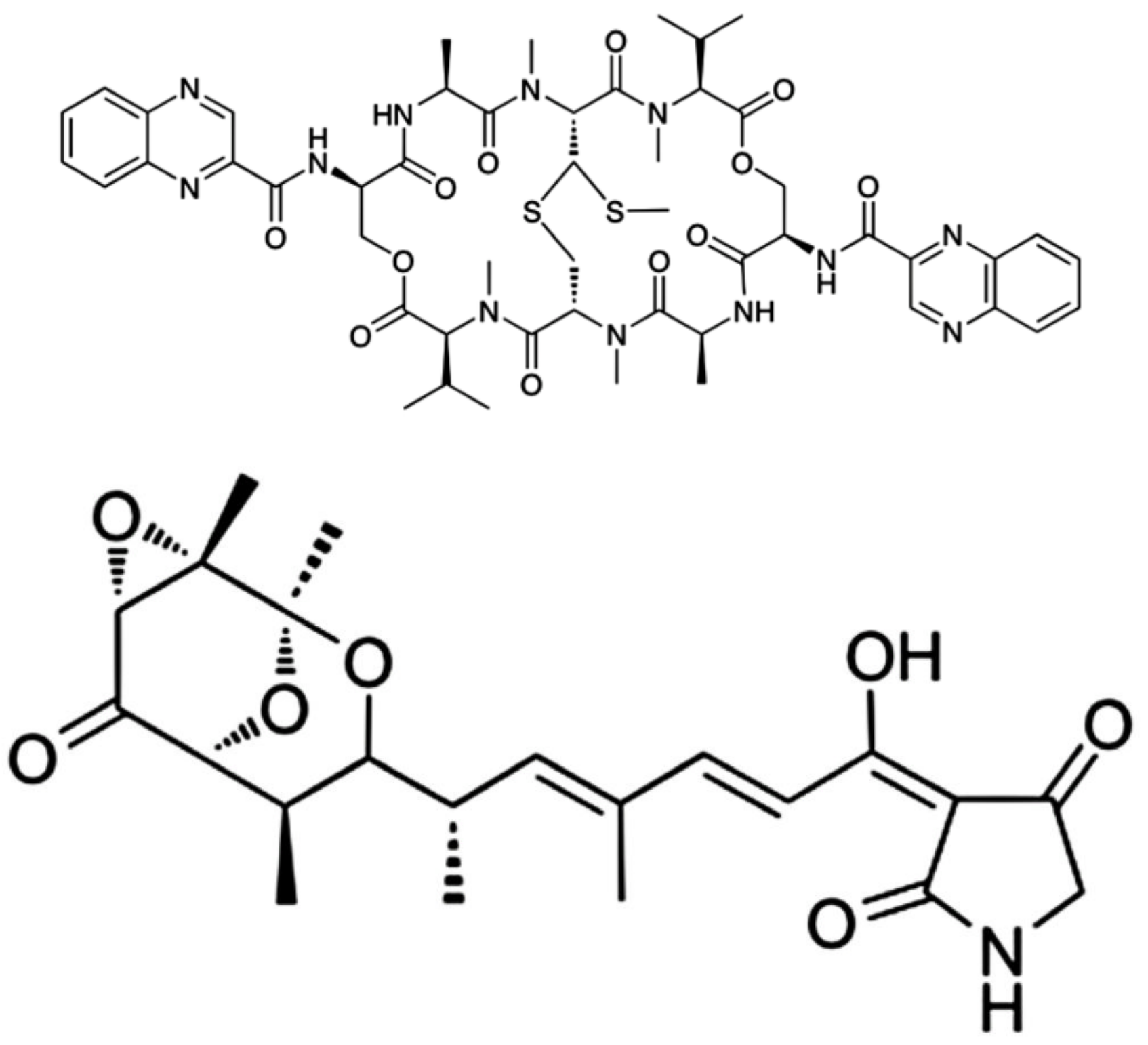

Figure 1. 


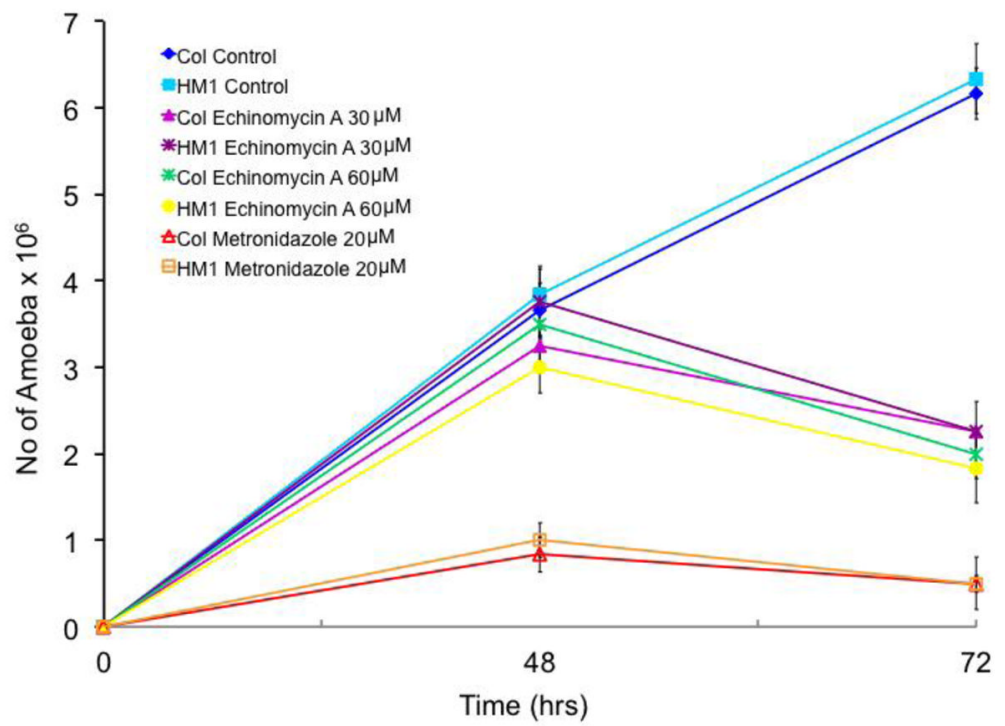

Figure 2. 


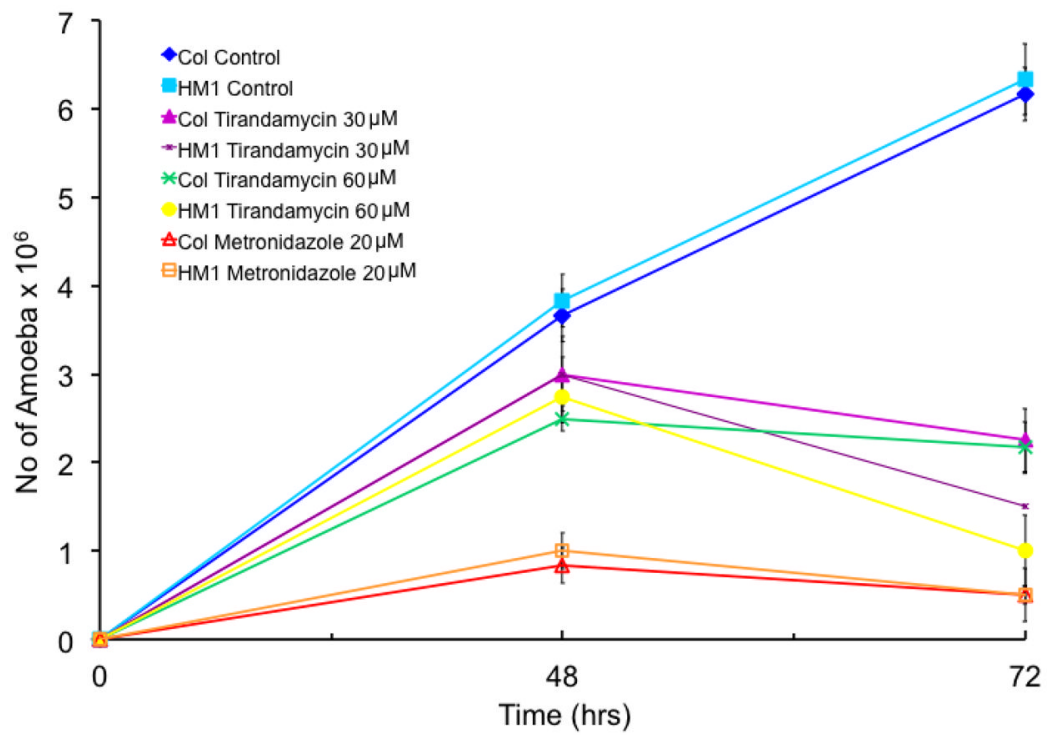

Figure 3. 
